\title{
LINGUAGEM DOCUMENTÁRIA NO DOMÍNIO DA VIGILÂNCIA SANITÁRIA NO BRASIL E A SUA QUALIDADE PARA A REPRESENTAÇÃO DE LEGISLAÇÃO
}

\author{
Pablo Gomes \\ pablogomes.pg@gmail.com \\ Virginia Bentes Pinto \\ Doutora em Informação e Comunicação \\ Universidade Federal do Ceará \\ bentespinto@yahoo.combr
}

Faculdades Integradas da União Educacional do Planalto Central

\section{Resumo}

\begin{abstract}
A Agência Nacional de Vigilância Sanitária possui atribuição de catalogar e indexar suas legislações na base de informação Saúde Legis, que utiliza o Tesauro do Ministério da Saúde (MS) como Linguagem Documentária (LD). Assim, surge a pergunta problema: qual a qualidade que o Tesauro do MS possui em representar o conteúdo de legislações sanitárias. O objetivo é verificar a qualidade da indexação das legislações sanitárias utilizando o Tesauro do MS. $\mathrm{Na}$ metodologia foram coletadas 70 Resoluções da Diretoria Colegiada relativas ao ano de 2014. Em seguida cotejou-se os termos da LN com a LD para verificar a relação de correspondência entre as duas linguagens. Os resultados apontam que $66 \%$ dos termos da LN possuíam correspondentes na $\mathrm{LD}, 24 \%$ não possuíam termos e $10 \%$ possuíam termos não tão apropriados na $\mathrm{LD}$. A conclusão mostra que os termos não estão apresentando qualidade suficiente para atender a especificidade da representação em vigilância sanitária.
\end{abstract}

Palavras-chave: Qualidade na Indexação. Representação Temática da Informação. Linguagem Documentária. Vigilância Sanitária.

\section{INTRODUÇÃO}

No Brasil o órgão público responsável pela saúde dos brasileiros é o Ministério da Saúde (MS). Esse órgão possui outros órgãos ligados a ele e que trabalham nos diversos campos da saúde. Nas ações de saúde pública relativas à certificação de produtos e serviços para a saúde a atribuição de regulamentação, controle e monitoramento é da Agência Nacional de
Vigilância Sanitária (Anvisa), isso no âmbito federal.

Para que a Anvisa possa executar suas ações, essas devem estar subscritas em legislações. Essa premissa não foge da ação do Estado, que deve agir dentro da legalidade. Assim, pressupõe-se que haja uma grande quantidade de legislações produzidas no que se refere à saúde, visto pela sua extensão.

Notando a quantidade de legislações relativas à saúde, o MS verificou que 
eram necessárias ações de controle, para que essas legislações pudessem ser recuperadas em algum momento, tanto por instituições públicas ou privadas como também pelos cidadãos.

Parecia inevitável a criação de um sistema onde fosse possível fazer esse controle. Foi assim que o MS criou o Saúde Legis. Esse sistema permite a recuperação das legislações em saúde que são editadas e publicadas no Brasil, no âmbito federal. De acordo com o MS o Saúde Legis "é o sistema de pesquisa de legislação que reúne os atos normativos do Sistema Único de Saúde (SUS), no âmbito da esfera federal. Estão disponíveis para consulta mais de 90 mil normas" (BRASIL, 2016).

Mesmo tendo iniciado suas atividades de representação da informação das legislações em 2003, foi somente em 2006 que o sistema foi liberado para pesquisa de usuários externos ao MS. Outro ponto que é relevante a trajetória do Saúde Legis vem do ano de 2010, quando o MS editou e publicou a Portaria $\mathrm{n}^{\circ} 460$, em 04 de março. Essa Portaria determina que todos os órgãos que se ligam ao MS devem incluir suas legislações de origem no Saúde Legis. Foi nesse contexto que a Anvisa iniciou suas atividades junto a essa base.

Mesmo que produza vários tipos de informação legislativa, como Portarias, Resoluções Executivas e a Agenda Regulatória, são as Resoluções da Diretoria Colegiada (RDC) a principal legislação que a Anvisa cadastra no Saúde Legis. Junto a base a Biblioteca da Anvisa precisa catalogar e indexar as RDCs. Para padronizar a representação e a recuperação da informação o MS criou e adotou uma Linguagem Documentária, o Tesauro do Ministério da Saúde. Esse Tesauro inicialmente foi criado para atender as traduções documentárias das legislações do MS, legislações gerais, e não legislações específicas como as da Anvisa, Agência Nacional de Saúde
Suplementar e Fundação Nacional de Saúde.

No momento da indexação a biblioteca encontrou uma grande dificuldade, pois perceberam que o Tesauro do Ministério da Saúde contemplava de forma mínima uma estrutura de termos da área especializada da vigilância sanitária, já que havia sido criado para atender demandas de termos da saúde de forma geral. Isso faz com que haja a inserção de vários termos não tão adequados para poder representar o assunto dos documentos dessa área. Essa colocação mostra que a estrutura do Tesauro em relação a formação de termos em vigilância sanitária pode estar afetando a representação temática das legislações. Assim, é necessário que haja verificações constantes relativas a essa pontuação para identificar a eficiência da LD.

Os estudos relativos às LDs apesar de muito atuais são de longa data e a cada dia vem se mostrando cada vez mais necessários, principalmente no que diz respeito em identificar se essas linguagens estão sendo utilizadas com a eficiência desejada. Desde o final do século passado a professora da Universidade de Coimbra Isabel M. Ribeiro Ferin Cunha (1990, p. 19) já apontava que

$\begin{aligned} & \text { Uma das linhas de pesquisa mais } \\ & \text { relevantes em }\end{aligned}$
Biblioteconomia/Documentação é a
questão da linguagem documentária, no
singular, enquanto sistema geral, e, no
plural, enquanto processos
diversificados capazes de traduzir
conteúdos de documentos em
"informações".

Mesmo tendo se passado mais de 25 anos, o discurso da professora Isabel Cunha não se modificou e continua sendo uma realidade. $\mathrm{Na}$ verdade parece que esse discurso se intensificou, especialmente devido ao número de LDs que surgiram com o avanço da tecnologia, tanto de representação como de 
recuperação da informação. É necessário comentar que o estudo das LDs é extremamente importante, isso devido a possibilidade de identificar a eficiência dessas linguagens não somente para a representação, mas também para a recuperação, pois uma representação com pouca qualidade implica em um silencio na recuperação.

No contexto apresentado, das Linguagens Documentárias e da representação da informação em vigilância sanitária coloca-se como pergunta norteadora dessa pesquisa o seguinte questionamento: qual a qualidade que o Tesauro do Ministério da Saúde brasileiro possui em representar o conteúdo de legislações em vigilância sanitária?

Com vistas a responder essa pergunta foi traçado como objetivo principal verificar a relação de qualidade dos termos do Tesauro do MS possui para representar os conteúdos das legislações em vigilância sanitária.

\section{PRODUÇÃO E CONTROLE DA LEGISLAÇÃO EM DA VIGILÂNCIA SANITÁRIA}

Para que as ações da vigilância sanitária tenham validade perante as instituições que trabalham ofertando produtos ou serviços em saúde é necessário que elas possuam base legal, e por consequência validade jurídica. Para tanto se necessita que os legisladores mantenham o ordenamento jurídico sanitário atualizado às mudanças que ocorrem no mercado da saúde. Entretanto o Poder Legislativo não conseguem elaborar e aprovar legislações na velocidade das mudanças do mercado, pois além do campo da saúde precisam legislar em outras instâncias.

Moraes (2001) faz um apontamento sobre essa questão dizendo que as legislações, em especial em saúde, não podem esperar pelos tramites do Poder
Legislativo para que possam ser aplicadas. Sendo assim, o Poder Legislativo transfere atribuição, limitada, ao Poder Executivo para que esse legisle sobre certas matérias. A Anvisa possui essa atribuição, que foi dada pelo próprio Legislativo na lei de sua criação, Lei 9.782, de 26 de janeiro 1999, como consta no Art. 15 "III - editar normas sobre matérias de competência da Agência" (BRASIL, 1999).

Pela abrangência das áreas de atuação da vigilância sanitária é de se esperar que a Anvisa produza uma grande quantidade de legislação. Moraes (2001, p. 50), apenas 3 anos após a criação da Agência, já apontava para uma produção bastante acentuada de legislações:

[...] observamos na prática que órgãos da administração pública vêm habitualmente expedindo portarias com o intuito de regulamentar certas matérias, equiparando esse instrumento ao regulamento previsto no art. 84, inciso IV, da Lei Maior, não fugindo à regra, a Agência Nacional de Vigilância Sanitária, como pode-se observar das constantes portarias e resoluções por ela editadas e publicadas em Diário Oficial da União, ao longo de sua criação.

A Resolução da Diretoria Colegiada (RDC), é a principal legislação publicada pela Anvisa e um dos objetos de estudo dessa pesquisa. Essa Resolução se configura em um "ato normativo cujo objetivo é detalhar as áreas de ação da vigilância sanitária e suas normas de organização" (Agência..., 2009, p. 18). É por meio da RDC que há a formalização das ações da vigilância sanitária, essas com base legal e valor jurídico, pela qual a Agência intervém no setor regulado.

A Anvisa intervém no setor regulado por meio de instrumentos próprios como, por exemplo, pela edição de Resoluções da Diretoria Colegiada (RDCs) e de Resoluções (REs). Semelhantes na nomenclatura, esses instrumentos se 
distinguem em relação à finalidade e ao processo de aprovação interna. (AGÊNCIA..., 2007, p. 48).

Com essa produção de legislações era necessário que se criassem mecanismos de controle. A importância que é dada ao controle dessas legislações, ou melhor informações, está em torno de três pilares como apontado por Costa (2004), a própria vigilância sanitária, o setor regulado e também o cidadão. Assim, tem se que o controle não é previsto somente para a vigilância sanitária, ele é necessário para que o setor regulado e os cidadãos possam acessar essas informações sempre que necessário.

Costa (2004, p. 64) também destaca que:

A questão da informação, organizada segundo perspectiva de 'um olho no mercado' e um 'olho na saúde' conforma um subsistema de acompanhamento do 'mundo dos produtos, serviços $\mathrm{e}$ ambientes' e do estado de saúde da população, especificamente por indicadores relacionados a com os objetivos da Vigilância Sanitária.

Isso significa dizer que o controle da informação é necessário para que haja também um acompanhamento das ações da vigilância sanitária pelos outros setores da saúde, pelo setor regulado (produtores e prestadores) e também pelos cidadãos, que precisam conhecer as normas sanitárias para que possam se adequar e também para que possam cobrar a sua aplicação.

Para que do controle dessas informações possa surgir uma disponibilização eficiente para a busca e recuperação é necessário que elas sejam representadas informacionalmente de forma adequada.

\section{REPRESENTAÇÃO DA INFORMAÇÃO EM SAÚDE}

No contexto da Ciência da Informação
(CI) a representação é um campo de estudo e fundamental as atividades biblioteconômicas. É nesse caso a representação da informação. Assim, para a CI e biblioteconomia, pode-se dizer de forma simples que seria apresentar de uma forma diferente os objetos informacionais do mundo real. Para tanto são utilizados elementos simbólicos que são colocados em um contexto limitado que representem uma informação.

A utilização de elementos simbólicos inseridos em um contexto limitado é corroborada por Lima e Alvares (2012) que aponta a representação como uma ação onde são utilizados elementos como palavras, figuras, imagens e outros com o intuito de assumir um objeto, uma ideia ou um fato e Makowiecky (2003) indicando que essa deve estar posta em um contexto limitado. Dessa forma, tudo que estivesse fora desse contexto não poderia ser considerado representativo.

Uma das formas de se representar uma informação é a temática, no caso dessa pesquisa voltada a indexação. Nessa forma de representação o profissional da informação irá, de acordo com Naves (1996, p. 215), "identificar e descrever um documento de acordo com seu assunto". Isso importa dizer que, a indexação é a representação do que é intrínseco a um documento, da sua natureza, daquilo que lhe é essência, do que the constituí como obra intelectual.

Para que o trabalho de identificação do assunto de documentos seja feita a NBR 12.676:1992 (ABNT, 1992, p. 2) identifica três etapas no processo de indexação, que são elas, a) exame do documento e estabelecimento do assunto de seu conteúdo; b) identificação dos conceitos presentes no assunto e c) tradução desses conceitos nos termos de uma linguagem de indexação. Essa norma aborda que esses três estágios não são distintos um do outro, pois se sobrepõem.

Esses comentários sobre representação da informação se tornam relevantes para o seu entendimento no contexto da saúde, pois essa área se resguarda de especificidades que torna única a sua atividade. De acordo com Bentes Pinto e Silva Neto (2013) a representação em saúde não pode ser pensada como a indexação de outras áreas. Essa possui especificidades que tornam a sua prática totalmente diferenciada. É importante, então, que os indexadores estejam preparados à visualizar 
as peculiaridades dessa área e a trabalhar em todas as suas especificidades.

Nisso temos que no contexto limitado da saúde é necessário que haja um cuidado diferenciado na utilização de elementos simbólicos para que esses representem adequadamente a informação em saúde. Para Bentes Pinto e Silva Neto (2013, p. 164) no contexto da saúde a

[...] seleção de um conceito simples, pode não ter a garantia literária sobre o que está descrito nesses documentos e, portanto, a recuperação da informação traduz-se-á em ruídos, ou mesmo silêncios, não se concretizando a tão sonhada mediação que tanto se propaga. Talvez uma boa solução seja o uso de sintagmas mais complexos.

Como apresentado, a utilização dos elementos simbólicos apontados por Lima e Alvares (2012) devem ser utilizados de acordo com as especificidades da saúde, abrindo-se mão da prática de outras áreas do conhecimento. Para Bentes Pinto e Silva Neto (2013) a utilização de sintagmas, que são mais complexos que os termos simples, seriam uma das especificidades da reapresentação da informação no âmbito da saúde.

A utilização dos elementos simbólicos textuais, termos ou sintagmas, são utilizados na etapa "c" da NBR 12.676:1992 apontada anteriormente como a "tradução desses conceitos nos termos de uma linguagem de indexação" (ABNT, 1992, p. 2. Para uma maior eficiência no processo de representação e recuperação da informação buscam-se mecanismos e ferramentas para a padronização de utilização desses elementos. Assim, são utilizadas Linguagens Documentárias (LDs) que cumprem esse papel de uniformização na utilização de termos para a representação da informação, já que de acordo com Lange (2001) a Linguagem Natural não é muito recomendada à indexação por não haver um controle sobre o vocabulário e assim dificultar no processo de recuperação da informação.

Na conceituação de Dodebei (2002, p. 53) as LDs "são, portanto, metacódigos ou metalinguagens, pois são construções artificiais ou convenções criadas para facilitar o conhecimento de um domínio, regidas por regras de utilização". Cintra et al. amplia o entendimento dizendo que "as linguagens documentárias (LD) estão intimamente ligadas à comunicação da informação e, metaforicamente, podem ser consideradas como a ponte entre a informação e o usuário que a necessita".

Novamente buscando o contexto da saúde é importante comentar que se a indexação de informações nesse campo do conhecimento deve ser feita de forma distinta de outras áreas por guardar especificidades, tem-se que colocar que os instrumentos de representação também devem ser pensados de forma diferenciada. Nisso, as LDs utilizadas no domínio da saúde devem ser específicas para área da saúde e trazer ao indexador a possibilidade de suprir as especificidades dessa área.

Uma LD amplamente utilizada é o tesauro, que para Currás (2010, p. 82) “é um sistema de classificação de matérias formado por termos conectados de uma certa maneira". Abrangendo mais o conceito do tesauro Vieira, Santos e Lapa (2010, p. 72) apontam que o tesauro é uma:

[...] ferramenta que permite um controle dos termos atribuídos na indexação, tornando-a mais eficaz, pode vir a exercer um grande papel viabilizando entre outras coisas servir como instrumento de apoio a organização, representação e recuperação de informações mais precisa de um grupo específico de usuários.

Na Norma ANSI Z39.19 (NATIONAL..., 2005, p.9) o conceito de tesauro é de "um vocabulário controlado organizado em uma ordem preestabelecida e estruturado de modo que os relacionamentos de equivalência, de 
homografia, de hierarquia, e de associação entre termos sejam indicados claramente e identificados por indicadores de relacionamento padronizados".

Os tesauros são ferramentas que auxiliam os indexadores no processo de indexação e tornam mais clara as relações entre os assuntos do texto e os descritores, termos ou sintagmas, que são escolhidos para a indexação. Nele são criados mecanismos para o controle da entrada de termos com o intuito de evitar a duplicidade de termos, criação de uma hierarquia e também para a visualização do tesauro como um sistema.

Porem, o tesauro por si só não garante a eficiência dos termos para a recuperação da informação pelos usuários, assim como propõe Lancaster $(2004$, p. 83) indicando que "a indexação não constitui um fim em si mesma". Essa eficiência será verificada pela qualidade que os temos possuem em representar a informação a qual fazem referência. Para que isso ocorra é necessário um controle de qualidade dos termos de indexação.

Esse controle de qualidade foi apontado por Bentes Pinto (2001) em que esse controle seria uma nova etapa a se cumprir após as já elencadas pela NBR 12.676:1992. Araújo Junior (2007) baseando-se nas colocações de Lancaster identifica alguns fatores que influenciam na "boa indexação", quais sejam, a) os fatores ligados ao indexador; b) fatores ligados ao vocabulário; c) fatores ligados ao documento; e d) fatores ambientais. Todos esses fatores mencionados são influenciadores da qualidade da indexação.

$\mathrm{Na}$ aceitação de que o processo de indexação é passível de erro e é totalmente influenciado por questões subjetivas que emerge também da necessidade de se haver um controle dos termos utilizados na indexação e de grande importância que haja uma avaliação da LD para a representação da informação.

\section{PROCEDIMENTOS METODOLÓGICOS}

Essa pesquisa é caracterizada como quanti-qualitativa de caráter exploratório, pois permite uma aproximação no entendimento sobre a indexação aplicada ao âmbito especializado da vigilância sanitária, bem como às linguagens de representação. Gil (2008, p. 27) aponta que essa pesquisa, exploratória, tem como objetivo "proporcionar visão geral, de tipo aproximativo, acerca de determinado fato. Este tipo de pesquisa é realizado especialmente quando o tema escolhido é pouco explorado e torna-se difícil sobre ele formular hipóteses precisas e operacionalizáveis".

Para analise dos dados fui utilizada a Análise de Conteúdo. Tal metodologia foi popularizada por Bardin (2011, p. 47) e configura-se como

[...] um conjunto de técnicas de análise das comunicações visando a obter, por procedimentos sistemáticos e objetivos de descrição do conteúdo das mensagens, indicadores (quantitativos ou não) que permitam a inferência de conhecimentos relativos às condições de produção/recepção (variáveis inferidas) destas mensagens.

No momento da coleta dos dados recorreu-se ao sistema de legislações Saúde Legis e ao Tesauro do Ministério da Saúde. O Saúde Legis é um sistema que permite o acesso e a recuperação das legislações em saúde que são editadas e publicadas no Brasil no âmbito federal. Conforme a Anvisa, o Saúde Legis se configura como sendo um "sistema de pesquisa de legislação que reúne os atos normativos do Sistema Único de Saúde (SUS), no âmbito da esfera federal, incluindo algumas normas publicadas pela Anvisa". (BRASIL, 2015, p.9). Já o Tesauro do MS:

O Tesauro do Ministério da Saúde lida com termos especializados da esfera federal do SUS e é utilizado para descrever livros, periódicos, documentos, legislação, etc. com o nível de especificidade desejado, permitindo, assim, a recuperação da informação que se procura. (BRASIL, 2015a) 
Escolheu-se para verificar a qualidade dos termos para a indexação de legislação sanitária as Resoluções da Diretoria Colegiada, isso por essas legislações serem um dos principais atos normativos expedidos pela Anvisa.

Inicialmente à coleta dos dados no Saúde Legis ocorreu sem a utilização da busca temática, mas utilizando as expressões de busca referentes aos dados descritivos das legislações. Assim, foi atribuído no campo de busca "Tipo de Norma" o tipo "RDC-Resolução da Diretoria Colegiada". No campo "Ano de Publicação" foi selecionado o ano de "2014". E por fim o campo de busca "Origem", que trata do órgão de origem da norma, foi selecionado a "ANVISAAgência Nacional de Vigilância Sanitária".

Dessa busca o sistema retornou com 70 (setenta) RDCs como resultado, que são Resoluções da Diretoria Colegiada que a Anvisa editou e publicou no ano selecionado.

Devido a fragilidade da informação na Internet, podendo ser alterada ou trocada, faz-se necessário identificar a data da coleta dos dados. Assim, essa pesquisa foi feita no dia 5 de outubro de 2015 onde foram coletadas as legislações em texto completo e os termos indexadores, atribuídos com a utilização do Tesauro do Ministério da Saúde, pelos indexadores da Anvisa.

Em seguida, tendo como base os textos completos das RDCs foram coletados, com uso da analise de conteúdo, os termos na LN do documento, selecionando-se no máximo 10 termos que poderiam representar com mais integridade os temas tratados em cada documento. Assim, fez-se a extração desses termos na linguagem natural das RDCs e depois foi feita a tradução para os termos da linguagem documentária, utilizando o Tesauro do MS, essa pesquisa iniciou dia 9 de outubro e se estendeu até o dia 16 de outubro de 2015.

Após a tradução os termos foram classificados em 3 categorias e atribuído cores a cada uma dessas, para facilitar a verificação de qualidade, Apêndice A. Dessa forma, os termos da LN com termo apropriado na LD ficaram com a cor verde, os termos da $\mathrm{LN}$ com termo não tão apropriado na LD com a cor laranja e os termos da LN sem termos na LD com a cor vermelha. Essa etapa tem o intuito de melhor verificar a relação de qualidade entre os termos da linguagem natural e os da linguagem documentária.

\section{ANALISE DOS DADOS}

Feito o estudo das RDCs ficou evidente que $66 \%$ dos termos utilizados no ano de 2014 na indexação desses documentos possuíam termo correspondente da LN para a LD, conforme o gráfico 1. Embora que do ponto de vista da coerência entre as linguagens esse percentual possa ser considerado, de certa forma elevado, ainda assim, para uma boa recuperação da informação indica-se que esse valor deveria ser acima de $95 \%$.

Gráfico 1 - Relação de qualidade entre os termos da LN com os termos da LD.
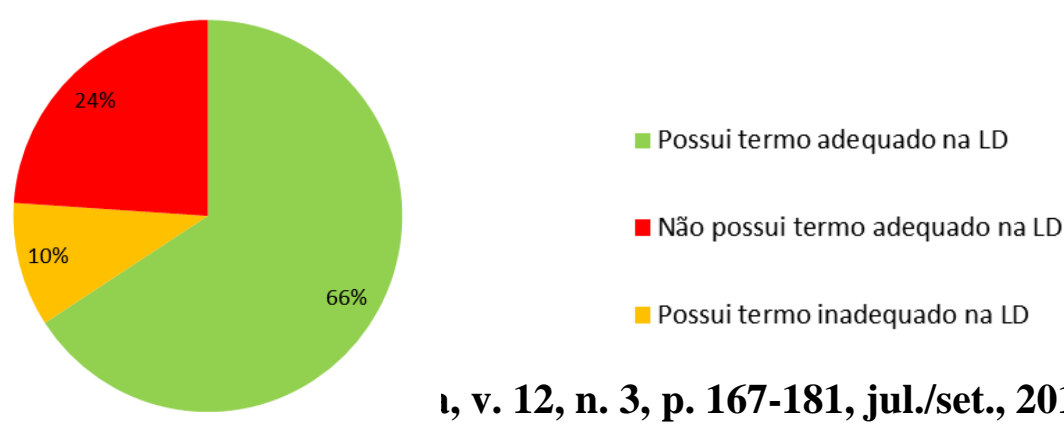

I, v. 12, n. 3, p. 167-181, jul./set., 2016 
Fonte: Dados da pesquisa empírica.

Referente aos termos da $\mathrm{LN}$ e que possuíam correspondente na LD constatou-se que eles são geralmente de uso geral na saúde, já que o Tesauro do Ministério da Saúde foi elaborado para receber demanda desse órgão maior. Nesse interim salta aos olhos a terminologia legislativa, como foi o caso do termo "suspensão" que apareceu 3 vezes, "resolução" em 4 casos, "atualização" que apareceu 6 vezes, "aprovação" e "ato normativo" com 14 ocorrências cada um, "alteração" em 18 dos casos analisados e o de maior frequência foi "regulamento técnico" que apareceu em 22 casos. O que não poderia deixar de ser, afinal, tais termos estão contidos no escopo da legislação das RDCs, portanto, essa coincidência no cotejamento da $\mathrm{LN}$ com a $\mathrm{LD}$ ratificam a coerência entre as linguagens documentarias.

Por sua vez identificou-se que $24 \%$ dos termos mapeados na redação das RDCs, número significativo quando se fala em recuperação de informação, não estavam incluídos na LD utilizada. Talvez isto seja consequência da especialidade dos termos da vigilância sanitária. Porém também depende do avanço da ciência e da tecnologia demonstrando que a terminologia das áreas de conhecimento está em constante evolução fazendo surgir termos, conceitos ou expressões no contexto das especialidades. Esses dados podem demonstrar que o Ministério da Saúde (MS) não vem atualizando de forma sistemática o Tesauro como deveria, isto é, no que tange os termos relativos a vigilância sanitária. Talvez uma solução para evitar que haja silêncio na recuperação da informação fosse que esse Tesauro permanecesse um tesauro geral da saúde.

Um entendimento que pode ser apontado como como necessário é que os órgãos que compõem a pasta do MS, como a Anvisa, construíssem seus próprios tesauros, devido a pertinência de suas especificidades. Tal política contribuiria para que houvesse o alinhamento desses tesauros específicos com o Tesauro do MS e, desse modo, haveria a possibilidade de atualização do tesauro com a inclusão de termos novos. Como se pode observar, não é possível negar a presença de neologismos também no âmbito da documentação redigida pela Anvisa. O que não pode-se é deixar de estar atentos a esses aspectos, daí a necessidade de um trabalho conjunto de uma equipe multidisciplinar que possa atualizar o Tesauro de acordo com a terminologia da LN.

Outro aspecto dos achados da pesquisa é que $10 \%$ dos termos encontrados na redação das RDCs possuía termo inadequado com a da $\mathrm{LD}$, isto é, não enunciavam, na sua inteireza, o termo da LN. A solução encontrada pelos indexadores da Anvisa foi a utilização de termos não similares, muito genéricos ou ainda a união de dois ou mais termos para formar um conceito. Como foi o caso de "transporte de material biológico humano" representado somente por "material biológico" e também de "família de medicamentos" que foi representado pela junção de "família" e "medicamento". Esses casos serão melhor apresentados durante a discussão.

A formação desses novos termos foi um dos resultados da pesquisa mais importante, pois demostra que os indexadores da Anvisa já perceberam a defasagem do Tesauro do Ministério da Saúde em relação a termos da vigilância sanitária e passaram a fazer a associação de dois termos para que esses formassem um sintagma representativo do termo da LN.

Essa formação de novos termos feita pela Anvisa é somente um paliativo para a tradução dos termos selecionados nas RDCs utilizando o Tesauro. Esse tipo de atitude está em desacordo com a 
motivação da utilização de uma LD, pois há a adoção de termos dissociados de seus conceitos. Esse é o caso constatado na RDC 59/2014. O conteúdo dessa norma se refere à formação de "famílias de medicamentos".

De acordo com o Artigo $4^{\circ}$, parágrafo IV, dessa RDC o conceito de "família de medicamentos" é entendido como "conjunto de produtos farmacêuticos de uma mesma empresa, com mesmo(s) fármaco(s) identificador(es), agrupados por um nome comum e diferenciados por complementos individuais" (AGÊNCIA..., 2014, p. 01).

A inexistência desse termo no Tesauro fez com que a Anvisa optasse pela utilização de dois termos separados a seus conceitos, "família" e "medicamentos" para a formação de um novo termo, Figura 1.

Figura 1 - Espelho da RDC 59/2014.

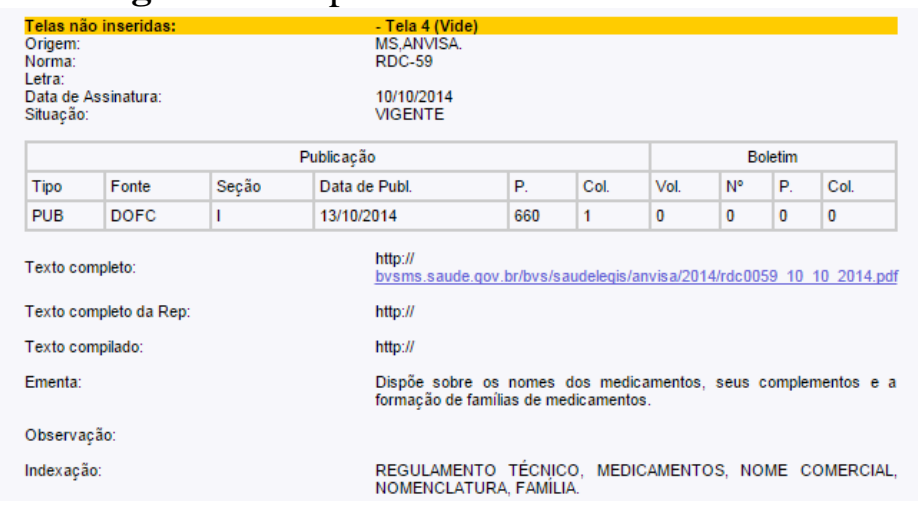

Fonte: BRASIL. Ministério da_Saúde. $2015 \mathrm{~b}$.

Porém, se forem visualizados os conceitos relativos a esses termos vê-se que há a formação de um novo termo com um erro conceitual relativo à união dos dois conceitos. "Família" refere-se a um grupo de pessoas que mantém vínculo sanguíneo ou afetivo, como mostra a Figura 2.

Figura 2 - Conceitos do termo "família" no Tesauro do Ministério da Saúde.

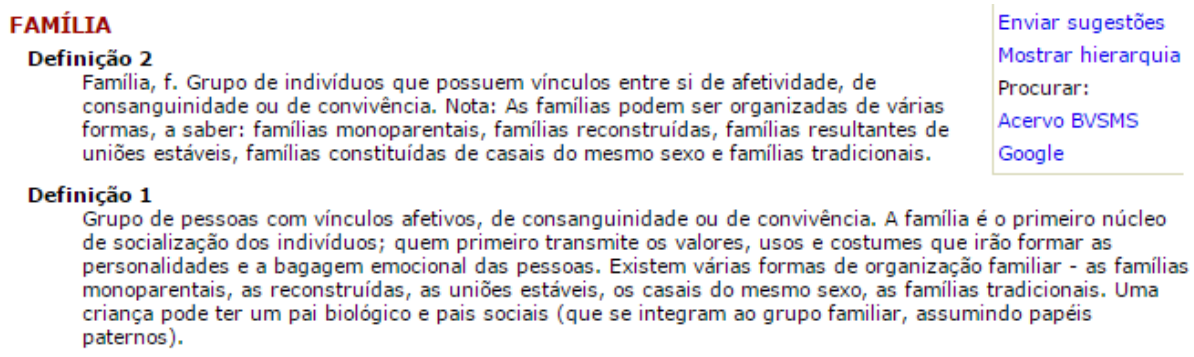

Fonte: BRASIL. Ministério da Saúde. 2015a.

Já "medicamento" é adotado para fórmula farmacêutica utilizada de forma profilática, curativa ou paliativa em relação a doenças, Figura 3. 
Figura 3 - Conceitos do termo "medicamento" no Tesauro do Ministério da Saúde.

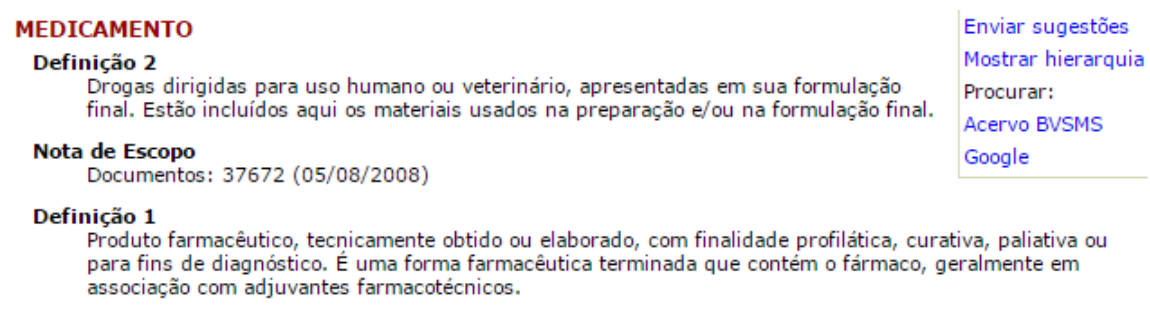

Fonte: BRASIL. Ministério da Saúde. 2015a.

Desse modo, a união desses dois conceitos para na formação do novo termo necessário a indexação dessa RDC formaria um novo conceito errado, pois não há relação entre os conceitos iniciais que justifiquem o surgimento de um terceiro conceito coerente.

Uma busca rápida no Saúde Legis foi feita para se entender o comportamento dessa formação, onde utilizou-se a expressão de busca "família de medicamentos" e o sistema retornou com 9 resultados, porém nenhum deles correspondia a RDC 59/2014, que está indexada com os termos "família" e "medicamento". Em seguida recorreu-se a uma busca termo a termo com o operador booleano "e" em que o sistema não retornou nenhum resultado.

Relativo ao caso de utilização de falsos similares ocorreu com a RDC 25/2014 cujo termo da LN é "requisitos mínimos de identidade e qualidade" e o termo da LD é "padrão de identidade e qualidade". Esses dois foram utilizados como sinônimos, entretanto "requisitos mínimos" e "padrão" podem não se referir a um mesmo conceito, porém a utilização dos mesmos dá a entender que são. É necessário um estudo mais aprofundado em relação a utilização desses dois termos para saber se em relação a vigilância sanitária eles são sinônimos ou não. Sendo sinônimos, a utilização do termo está correta, não sendo eles estarão em desacordo com o conteúdo da RDC.

Há que se comentar também sobre a utilização de termos muito genéricos. Nesse caso, pode-se apontar os exemplos dos termos "princípios ativos semisintéticos", "certificado de boas práticas em bioequivalência", "rede sentinela", "dispersão de medicamento", "insumos farmacêuticos ativos" e "veículos para a preparação de enzimas", que apesar de possuírem pouca ocorrência, uma ou duas vezes no total das RDCs analisadas, tem grande impacto na representação dos termos aos quais se referem. Esses casos de ocorrência são de termos que fazem parte do cotidiano das regulamentações da vigilância sanitária, mas que devem aparecer raramente ou nem aparecer nas regulamentações do Ministério da Saúde ou dos outros órgãos ligados a ele.

Percebeu-se, durante a coleta e analise dos dados, que os termos relativos à vigilância sanitária estão em uma formação genérica, não chegando a termos específicos. Essa formação muito genérica interfere na tradução dos termos da $\mathrm{LN}$ para a $\mathrm{LD}$, pois, geralmente, o conteúdo da RDC é focado em um termo específico que não consta no Tesauro.

Essa dificuldade de encontrar os termos específicos também interfere na qualidade na indexação das RDCs relativas à vigilância sanitária, pois a indexação dessas Resoluções se mantem em um plano muito geral com outras normas que são diferentes conceitualmente.

Um caso que pode ser pontuado, relativos a utilização de termos gerais, é o da RDC 20/2014. Para a indexação dessa norma um dos termos da $\mathrm{LN}$ era "transporte de material biológico 
humano" já para a LD foi usado o termo "material biológico". Esse termo é muito geral quando tratado dentro da vigilância sanitária, pois engloba os materiais biológicos humanos, animais e vegetais.

Comenta-se também sobre a RDC 24/2014, que ocorreu durante a coleta em que o termo na LN é "seringas hipodérmicas estéreis de uso único". A tradução foi feita para a utilização do termo "seringa". Esse termo é tão geral que um termo na LD estaria pelo menos a um terceiro nível hierárquico.

A especificidade desse termo é tão grande que foi impossível a formação de um novo termo a partir da junção de termos separados. Foi então que a Anvisa decidiu pela utilização somente do termo geral.
Os termos da LN das RDCs da Anvisa já se apresentam na forma de uma Linguagem de Especialidade, pois são escritas com termos especializados e muitas vezes específicos da vigilância sanitária. Indexar esses termos de forma geral é negligenciar as especificidades da linguagem em que a vigilância sanitária se comunica.

Um problema identificado quanto a pouca existência de termos específicos se apresentou no momento de analise da RDC 03/2014. Ela trata de saneantes de forma geral. Durante o cotejamento entre o sistema Saúde Legis e o Tesauro foi verificado que o Tesauro indica que o termo autorizado para "saneantes" é o termo "saneantes domissanitários", como pode ser visto na Figura 4.

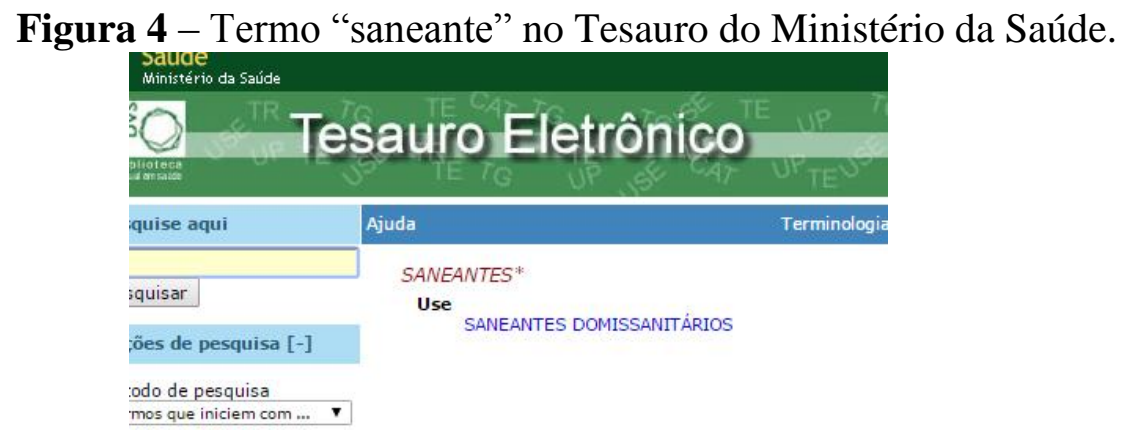

Fonte: BRASIL. Ministério da Saúde. 2015a.

"Saneantes domissanitários" é um termo específico de "saneantes", mas o Tesauro o coloca como termo não autorizado por motivos desconhecidos. Entretanto, um dos motivos que pode ser levantado é o Ministério ter considerado que se tratava de termos sinônimos.

A possibilidade de adoção de um termo geral foi interrompida, pois o Tesauro identifica a utilização de um termo específico. Essa situação é estranha visto que o Tesauro, quando trata a vigilância sanitária, geralmente é formado de termos gerais e poucos termos específicos e no momentos em que o uso de um termo geral foi solicitado, o Tesauro colocou que deveria ser empregado o termo específico.

É importante salientar que todas essas observações, em ralação aos termos da $\mathrm{LN}$ e da $L D$, que foram feitas sobre a indexação das RDCs do ano de 2014 são relevantes, pois são elas que indicam a qualidade que essa indexação apresenta. É em relação a esses termos que o usuário do sistema Saúde Legis irá conseguir recuperar ou não uma RDC em relação a uma busca por assunto especifico.

\section{CONCLUSÕES}

As Linguagens Documentarias são construídas com o propósito de padronizar a linguagem de comunicação do sistema com a linguagem do usuário no momento da 
formulação da expressão de busca. Por serem criadas com um objetivo especifico essas linguagens devem, na sua perspectiva de criação, exercer com a finalidade de qualquer outra LD, comunicação padronizada entre os sistemas de recuperação da informação e o usuário. Assim, é necessário verificar se a padronização tão desejada pelas LDs está sendo realmente efetiva. Não se pode chegar a um acomodamento e acreditar que uma LD por si basta para que haja eficiência no processo de representação e recuperação de uma informação.

Assim, após confrontados e analisados os dados quantitativos e qualitativos chegou-se a conclusão de que o Tesauro do Ministério da Saúde, LD adotada para a representação de legislação em saúde, não vem apresentando qualidade suficiente para a representação das legislações da vigilância sanitária federal. Por mais que se possa argumentar, pelos dados quantitativos em que a maioria dos termos da LN possui correspondente na $\mathrm{LD}$, para uma analise qualitativa é muito pequeno, principalmente, verificando que $34 \%$ dos termos da LN não estavam coerentes com a $\mathrm{LD}$, valor verificado na soma dos termos da LN que não possuíam termo na $\mathrm{LD}, 24 \%$, com os termos da LN inadequado na LD, $10 \%$.

A relevância dos termos sem coerência está apontado para o momento da recuperação de uma informação, isso não visualizando somente os dados quantitativo, esses podem ser um ponto de fraco para usuários que não conseguem formular de forma adequada as suas necessidades de informação para montar uma estratégia de busca. O auxilio de um bibliotecário poderia suprir, mas nem tanto, a deficiência de qualidade dos termos, mas nem sempre os usuários possuem essa ajuda, principalmente, que se trata de um sistema remoto e que pode ser acessado de qualquer local com acesso a Internet.

O paliativo, união de termos separados aos seus conceitos, que a Anvisa vem adorando para a tentar diminuir os problemas de recuperação da informação não demonstra uma imperícia ou inaptidão dos indexadores da Agência, mas para a necessidade de suprir as deficiências de termos que o Tesauro está apresentando.

Propõe se por fim que a Anvisa e o MS procurem uma solução para a melhoria da qualidade dos termos específicos da vigilância sanitária dento do Tesauro. Duas propostas iniciais podem ser apontadas, uma sendo a atualização e do Tesauro do MS e a outra seria a construção de um tesauro especializado em vigilância sanitária, e feito pela própria Agência, para enriquecer as indexações e para se ter melhor qualidade nas respostas das buscas temáticas em um sistema de recuperação da informação.

A atitude de criação de um novo tesauro não invalida a LD criada pelo MS, mas o novo tesauro poderia ser um subsistema do tesauro principal. A Agência pode, para a validação de termos e garantia literária na atualização ou construção do tesauro usar as Resoluções da Diretoria Colegiada, pois a maioria delas possui um pequeno glossário de orientação sobre o significado de alguns termos no contexto da vigilância sanitária federal.

\title{
DOCUMENTARY LANGUAGE IN DOMAIN OF HEALTH SURVEILLANCE IN BRAZIL AND IT'S QUALITY TO REPRESENT LEGISLATION
}

\begin{abstract}
The Brazilian Health Surveillance Agency has assignment to catalog and index their legislation at the basis of information Saúde Legis, using the Thesaurus of the Ministry of Health (MS) as Documentary Language ( $L D)$. So, arises the problem question: what is the quality that the MS Thesaurus has in represent the content of health legislation. The purpose is to check the quality of indexing of health
\end{abstract}

Biblionline, João Pessoa, v. 12, n. 3, p. 167-181, jul./set., 2016 
legislation using the MS Thesaurus. At the methodology were collected 70 Resolutions of the Board of Directors on to the year 2014. Then was compared the terms of the $L N$ with the $L D$ to check the correspondence relationship between the two languages. The results point that $66 \%$ of the terms of $L N$ had correspondents in $L D$, $24 \%$ didn't have terms and $10 \%$ had terms not as appropriate in $L D$. The conclusion shows that the terms are not presenting sufficient quality to comply with the specificity of representation in health surveillance.

Keywords: Quality at the indexing. Thematic information representation. Documentary Language. Health Surveillance.

\section{REFERÊNCIAS}

ARAÚJO JUNIOR, Rogério Henrique de. Precisão no processo de busca e recuperação da informação. Brasília: Thesaurus, 2007.

AGÊNCIA Nacional de Vigilância Sanitária (Brasil). RDC no 59, de 10 de outubro de 2014. Dispõe sobre os nomes dos medicamentos, seus complementos e a formação de famílias de medicamentos. Diário Oficial da União, Brasília, DF, 13 out. 2014.

AGÊNCIA Nacional de Vigilância Sanitária (Brasil). Relatório anual de atividades da Anvisa: 2006. Brasília: Ministério da Saúde, 2007.

AGÊNCIA Nacional de Vigilância Sanitária (Brasil). Relatório de atividades: 2008. Brasília: Anvisa, 2009.

AGÊNCIA Nacional de Vigilância Sanitária (Brasil). Saúde Legis. Disponível em: $\langle$ http://s.anvisa.gov.br/wps/s/r/PBT>. Acesso em: 28 set. 2015.

ASSOCIAÇÃO Brasileira de Normas Técnicas. NBR 12.676/1992: Método para análise de documentos: Determinação de seus assuntos e seleção de termos de indexação. Rio de Janeiro, ABNT, 1992.

BARDIN, Laurence. Análise de conteúdo. São Paulo: Edições 70, 2011.
BENTES PINTO, Virgínia. Indexação documentária: uma forma de representação do conhecimento registrado. Perspectivas em Ciência da Informação, Belo Horizonte, v. 6, n. 2, p. $223-234,2001$.

BENTES PINTO, Virgínia. SILVA NETO, Casemiro. Representação indexal como mediação informacional em prontuário de paciente. In: BENTES PINTO, Virgínia; CAMPOS, Henry de Holanda. (Orgs.). Diálogos paradigmáticos sobre informação na área da saúde. Fortaleza: UFC, 2013.

BRASIL. Lei $\mathbf{n}^{\mathbf{0}} \mathbf{9 . 7 8 2}$, de 26 de janeiro de 1999. Define o Sistema Nacional de Vigilância Sanitária, cria a Agência Nacional de Vigilância Sanitária, e dá outras providências. Diário Oficial da União, Brasília, DF, 26 jan. 1999.

BRASIL. Ministério da Saúde. Legislação básica do SUS. Disponível em: <http://portalsaude.saude.gov.br/index.php/ci dadao/legislacao>. Acesso em: 04 fev. 2016.

BRASIL. Ministério da Saúde. Saúde Legis. Brasília: MS, 2015b.

BRASIL. Ministério da Saúde. Tesauro do Ministério da Saúde. Brasília: MS, 2015a.

COSTA, Ediná Alves. Vigilância Sanitária: proteção e defesa da saúde. 2. ed. São Paulo: SOBRAVIME, 2004.

CUNHA, Isabel Maria Ribeiro Ferin. Do mito à analise documentária. São Paulo: EDUSP, 1990. 
CURRÁS, Emilia. Ontologias, taxonomias e tesauros em teorias de sistemas e sistemática. Brasília: Thesaurus, 2010.

DODEBEI, Vera Lucia Doyle. Tesauro: linguagem de representação da memoria documentária. Niterói: Intertexto; Rio de Janeiro: Interciência, 2002.

GIL, Antônio Carlos. Métodos e técnicas de pesquisa social. 6. ed. São Paulo: Atlas, 2008.

LANCASTER, F. W. Indexação e resumos: teoria e prática. 2. ed. Brasília: Briquet de Lemos, 2004.

LANGE, Evanilde Pereira Salles. Estudo teórico da análise documentária, análise do conteúdo e análise do discurso: os descritores de músicas que marcam época. Revista Varia scientia, n. 01, p. 113-121, 2001.

LIMA, José. Leonardo Oliveira; ALVARES, Lilian. Organização e representação da informação e do conhecimento. In: ALVARES, Lilian. (Org). Organização da informação e do conhecimento: conceitos, subsídios interdisciplinares e aplicações. São Paulo: B4Editores, 2012.
MAKOWIECKY, Sandra. Representação: a palavra, a idéia, a coisa. Cadernos de Pesquisa Interdisciplinar em Ciências Humanas, Santa Catarina, n. 57, p. 1-25, 2003.

MORAES, Eliana Aparecida de. O poder regulamentar e as competências normativas conferidas à Agência Nacional de Vigilância Sanitária. Revista de Direito Sanitário, Santa Catarina, n. 1, v. 2, p. 39-52, 2001.

NATIONAL Information Standards Organization. ANSI Z39.19: Guidelines for the Construction, Format, and Management of Monolingual Controlled Vocabularies. Baltimore: NISO, 2005.

NAVES, Madalena Martins Lopes. Análise de assunto: concepções, Revista de Biblioteconomia de Brasília, Brasília, v. 20, n. 2, p. 215-226, 1996.

VIEIRA, Jessica Monique de Lira; SANTOS, Monick Trajano dos; LAPA, Remi Correia. Estudo da construção e aplicação do tesauro na recuperação da informação de teses e dissertações do programa de pós-graduação em desenvolvimento urbano. Biblionline, João Pessoa, n. esp., p. 71-80, 2010.

APÊNDICE A

\begin{tabular}{|l|l|l|l|}
\hline \multicolumn{2}{|c|}{ RDC 67 } & \multicolumn{2}{c|}{ RDC 66 } \\
\hline LD & LN & LD & LN \\
\hline SUSPENSÃO & SUSPENSÃO & ALTERAÇÃO & ALTERAÇÃO \\
\hline $\begin{array}{l}\text { ATO } \\
\text { NORMATIVO }\end{array}$ & $\begin{array}{l}\text { ATO } \\
\text { NORMATIVO }\end{array}$ & $\begin{array}{l}\text { ATO } \\
\text { NORMATIVO }\end{array}$ & $\begin{array}{l}\text { ATO } \\
\text { NORMATIVO }\end{array}$ \\
\hline REGISTRO DE \\
MEDICAMENTO & $\begin{array}{l}\text { DOCUMENTO } \\
\text { INFORMATIVO } \\
\text { DE PREÇO } \\
\text { (documento }+ \\
\text { preçO) }\end{array}$ & $\begin{array}{l}\text { REGISTRO DE } \\
\text { PRODUTO }\end{array}$ & $\begin{array}{l}\text { FOLHETO } \\
\text { INFORMATIVO }\end{array}$ \\
\hline PROTOCOLO & $\begin{array}{l}\text { CÂMARA DE } \\
\text { REGULAÇÃO DO } \\
\text { MERCADO DE } \\
\text { MEDICAMENTOS }\end{array}$ & $\begin{array}{l}\text { REGISTRO DE } \\
\text { MEDICAMENTO }\end{array}$ & $\begin{array}{l}\text { PRODUTO } \\
\text { TRADICIONAL } \\
\text { FITOTERÁPICO }\end{array}$ \\
\hline DOCUMENTO & $\begin{array}{l}\text { REGISTRO DE } \\
\text { MEDICAMENTO }\end{array}$ & $\begin{array}{l}\text { MEDICAMENTOS } \\
\text { FITOTERÁPICOS }\end{array}$ & FITOTERÁPICO \\
\hline
\end{tabular}

Biblionline, João Pessoa, v. 12, n. 3, p. 167-181, jul./set., 2016 


\begin{tabular}{|c|c|c|}
\hline $\begin{array}{l}\text { PREÇO DE } \\
\text { MEDICAMENTO }\end{array}$ & $\begin{array}{l}\text { PLANTAS } \\
\text { MEDICINAIS E } \\
\text { FITOTERÁPICOS }\end{array}$ & $\begin{array}{l}\text { REGISTRO DE } \\
\text { MEDICAMENTO } \\
\text { FITOTERÁPICO } \\
\text { (registro de } \\
\text { medicamentos + } \\
\text { medicamentos } \\
\text { fitoteráficos) }\end{array}$ \\
\hline \multirow[t]{3}{*}{$\begin{array}{l}\text { CÂMARA DE } \\
\text { REGULAÇÃO DO } \\
\text { MERCADO DE } \\
\text { MEDICAMENTOS }\end{array}$} & $\begin{array}{l}\text { BULA DE } \\
\text { MEDICAMENTOS }\end{array}$ & $\begin{array}{l}\text { MEDICAMENTOS } \\
\text { FITOTERÁPICOS }\end{array}$ \\
\hline & $\begin{array}{l}\text { EMBALAGEM DE } \\
\text { MEDICAMENTOS }\end{array}$ & \\
\hline & $\begin{array}{l}\text { EMBALAGEM DE } \\
\text { PRODUTOS }\end{array}$ & \\
\hline
\end{tabular}

Biblionline, João Pessoa, v. 12, n. 3, p. 167-181, jul./set., 2016 